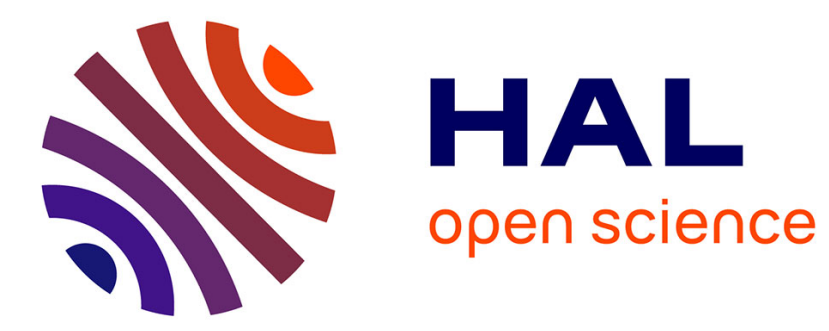

\title{
Perspectives on Accessibility in Digital Games
}

Jannicke Baalsrud Hauge, Neil Judd, Ioana Andreea Stefan, Antoniu Stefan

\section{To cite this version:}

Jannicke Baalsrud Hauge, Neil Judd, Ioana Andreea Stefan, Antoniu Stefan. Perspectives on Accessibility in Digital Games. 17th International Conference on Entertainment Computing (ICEC), Sep 2018, Poznan, Poland. pp.402-406, 10.1007/978-3-319-99426-0_51 . hal-02128639

\section{HAL Id: hal-02128639 \\ https://hal.inria.fr/hal-02128639}

Submitted on 14 May 2019

HAL is a multi-disciplinary open access archive for the deposit and dissemination of scientific research documents, whether they are published or not. The documents may come from teaching and research institutions in France or abroad, or from public or private research centers.
L'archive ouverte pluridisciplinaire HAL, est destinée au dépôt et à la diffusion de documents scientifiques de niveau recherche, publiés ou non, émanant des établissements d'enseignement et de recherche français ou étrangers, des laboratoires publics ou privés.

\section{(c)(1)}

Distributed under a Creative Commons Attribution| 4.0 International License 


\title{
Perspectives on Accessibility in Digital Games
}

\author{
Jannicke Baalsrud Hauge ${ }^{1,2}$, Neil Judd ${ }^{3}$, Ioana Andreea Stefan ${ }^{4}$, Antoniu Stefan ${ }^{4}$ \\ ${ }^{1}$ BIBA - Bremer Institut für Produktion und Logistik GmbH, \\ Hochschulring 20, D-28359 Bremen, Germany \\ baa@biba.uni-bremen.de \\ ${ }^{2}$ Royal Institute of Technology \\ Kvarnbergagatan 12, 15136 Södertälje, Sweden \\ jmbh@kth.se \\ ${ }^{3}$ Hands Free Computing Ltd, The Courtyard, Holmsted Farm, Staplefield Road, \\ Cuckfield, West Sussex, RH17 5JF; United Kingdom \\ Neil.judd@hands-free.co.uk \\ ${ }^{4}$ Advanced Technology Systems \\ Str. Tineretului Nr 1., 130029, Targoviste, Romania \\ \{ioana.stefan, antoniu.stefan\}@ats.com.ro
}

\begin{abstract}
Gaming technologies provides new ways of learning, but even though the new technologies have unique opportunities to support different individual needs, most games are not designed for people with impairments. This is specifically a problem in a learning context in mixed groups as well as for teachers with impairments who have to use the technology for preparing their classes. This paper focuses on how to make games for learning more accessible for students and teachers with different impairments.
\end{abstract}

Keywords: Accessibility, Educational Serious Games, Serious Game Design, Customisation, Choices, Alternatives

\section{Introduction}

Gaming technologies enable the construction of new learning environments that foster collaboration skills and creativity [1]. Pervasive Learning represents such new way of learning and it is defined as "learning at the speed of need through formal, informal and social learning modalities" [2]. The BEACONING project builds upon playful pervasive experiences and provides game-based, personalized learning paths. The focus is on STEM and on problem-based learning [3]. The BEACONING platform will provide the users (teachers, students) a set of applications that enable teachers to author gamified, customized lesson paths and students to play them. It is a clear goal of the project to make the Beaconing platform more accessible for people (students, teachers) with special needs, so that all students and teachers can use the same applications in a classroom setting. In general, the project looks at the following categories of impairment: a) visual impairment b) hear impairment c) mobility impairment and d) cognitive impairment. 
In this workshop paper, due to limited space, we have focussed on explaining how we can achieve better accessibility for visual impairments of games used for STEM education. The solution will be shown and discussed during the workshop.

\section{Accessibility and the Beaconing project}

Digital accessibility implies making an application or a website, with all of its data and functions, available for all users, regardless of how they interact with it, or what difficulties they might have (e.g. visual, hearing, or physical impairments; cognitive disabilities) [4]. Since the digital world is a visual medium, most of the efforts of making digital tools and websites accessible fall under visual accessibility. For example, for those with visual impairments there are a variety of alternate ways to access websites: use a screen reader that reads the content of a page back to them; override the default styling on a website, allowing individuals to use colours that are higher contracts or fonts that are easier to read; or increase the font size until it is legible. There are, however, several common issues that can occur when implementing such solutions: poorly structured html; images with no meaningful alt text; features that require vision; repetitive items that cannot be skipped; poorly structured forms.

Unlike websites and applications, digital games represent very dynamic environments, with specific gameplay, which make it difficult to implement such generic accessibility solutions, even in the case of basic HTLM-based games. In digital games, whether entertainment or educational ones, since the gameplay usually unfolds at a fast pace, it is difficult or even impossible to use a screen reader. Therefore, customized solutions are required. To fundament such customized solutions, it has become critical to identify best practices and provide recommendations, in order to support the large-scale implementation of accessibility features in digital educational games. There are many studies that discuss the pros and cons of using gaming as a mean of rehabilitation $[5,6,7,8]$. However, they focus mostly on the potential that gaming systems to support rehabilitation (e.g. enable personalized treatment recommendations) and less on the accessibility features that these games provide.

The BEACONING platform will enable the personalization of the learning units to the specific student's needs, including adaption for impairment. A gamified lesson path has in addition to a normal lesson plan several gamified elements, called minigames. Currently we have different forms of geo-location games, quests and quizzes as an integrated part of the lessons path. These minigames needs to be adapted and changed for the different students, and for this a authoring tool has been developed [5]. Also the graphical user interfaces for students and teachers need to be adaptable to sight impaired users. A more detailed description of the gamified lesson plan as well as different types of mini-games that are integrated can be found in [9, 10]. How this is realized is described in the next section. 


\section{$3 \quad$ Making games accessible}

The focus in this paper is on visual impairment. In addition to dyslexia, it is a common impairment also for teachers, which is quite easy to address, if thought of at an early stage[11].

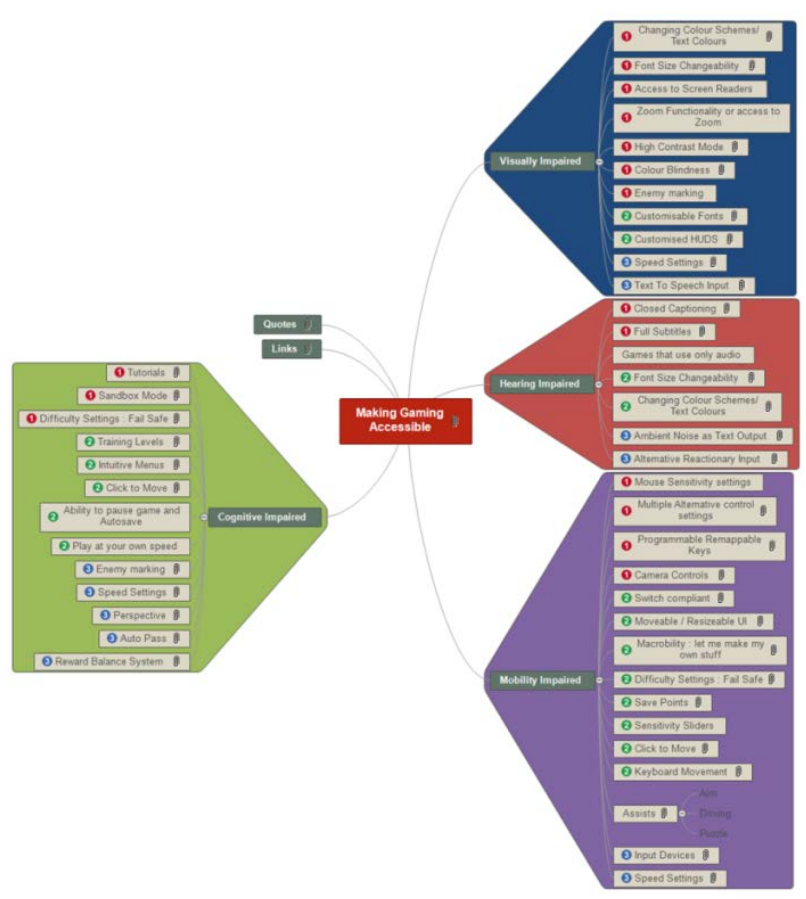

Figure 1: How to make games accessible

The core features in figure 1 and their implications for the accessibility are described below [11].

\section{- Changing Colour Schemes/ Text Colours 1}

For those that have difficulty distinguishing between colors, often referred to as color deficiency, the ability to change the color of text associated with a particular function improves overall gameplay. Note that color deficiency differs from color blindness. Color-deficient people can still see a certain color, but they cannot distinguish shades of the color, red vs maroon, or lime green vs dark green.

\section{- Font Size Changeability 1}

Gamers with visual difficulties including those that are legally or almost totally blind can still participate in many games, but reading text in the subtitles, directions/instructions and chats can be frustrating if the size of the text is just barely too small to read.

\section{- High Contrast Mode 1}


For First Person Shooters, it is extremely important that the target reticle uses colors that are easy to distinguish from the other environmental elements in the game. In situations where both the enemy and reticle are red, the user is unable to identify between the target and the sight, leaving no way to tell where the actual target is aiming

- Colour Blindness 1

Ideally all games should have colorblind options that can be enabled to compensate for a variety of color deficiency issues. The most prevalent of these disorders is the inability to tell the difference between the colors green and red. This is most often avoided by providing a way to change the color green to blue when indicating friendly information such as group mates or health bars.

\section{- $\quad$ Text To Speech Input 3}

Another top rated accessibility option would be to include the ability of the game to read the text on the screen and repeat it in audio form. Many programs now do this for users on the web, but it has not yet made its way into the game universe. The successful implementation of this feature would be to offer text-tospeech on user created text, like guild chat, or other chats created by end users.

\section{Implementation of these features in the BEACONING platform}

Beaconing draws upon this research to provide an experience not like any other with innovative tools for users with disabilities. These include a fully interactive toolbar interface called Accessabar which makes content accessible to users of all differing disabilities. A unique Accessibility Profile Wizard compliments this tool. Built into the account set up interfaces, the user will perform several simple exercises to determine whether certain accessibility features are needed in the main interface. Settings can be saved for individual user profiles. There will be differentiation but continuity in design between different user type portals, and the ability to switch in and out of roles within a single sign in account. For example, this allows a teacher to not only view and assign lesson plans within the Beaconing portal but also edit and configure them within the Authoring tool itself. Bring in the gamification, immersive gaming environment, compelling mini games and learning content of the highest quality and this is what sets Beaconing apart from the rest [12].

The figure below shows the some of the features already implemented in the Beaconing platform in order to increase the accessibility for sight impaired. Much more information is to be found in [6] which is the public deliverable. The toolbar is discreet and is accessed via the Accessibility link in the main navigation panel. A series of tools are presented in the toolbar all with their unique features which can manipulate text and objects on the screen making them accessible to all.

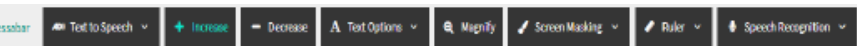




\section{$5 \quad$ Conclusions and next steps}

This article has reported on work carried out on doing educational games and learning platforms used for STEM education more accessible for students and teachers with sight impairments. It has presented design considerations for improving the accessibility and introduced the concept of Accessabar as a suitable solution. The platform is under evaluation before large scale pilots will start in autumn 2018.

\section{Acknowledgement}

The work presented herein is partially funded under the Horizon 2020 Framework Program of the European Union, BEACONING - Grant Agreement 68676

\section{References}

1. Ștefan, A. et al. (2016). Approaches to reengineering digital games. Proceedings of the ASME 2016, IDETC/CIE 2016

2. Pontefract, D. (2013). Learning by Osmosis. Retrieved from: http://www.danpontefract.com/learning-by-osmosis/

3. BEACONING Cons. (2017) D3.3 Learning Environment System Specification.

4. Cunningham, K. (2012). Accessibility Handbook, O'Reilly Media, Inc.,

5. Gauthier, L. V., Richter, T. A.,. George, L. C., Schubauer, K. M. (2018). Chapter 33 - Gaming for the Brain: Video Gaming to Rehabilitate the Upper Extremity After Stroke, Editor(s): Elliot S. Krames, P. Hunter Peckham, Ali R. Rezai, Neuromodulation (Second Edition), Academic Press, PP. 465-476.

6. Jurdi, S., Montaner, J., Garcia-Sanjuan, F., Jaen, J., Nacher, V. (2018). A systematic review of game technologies for pediatric patients, Computers in Biology and Medicine, Volume 97,Pages 89-112, ISSN 0010-4825,

7. Lv, Z., Esteve, C., Chirivella, J., Gagliardo, P. (2017). Serious game based personalized healthcare system for dysphonia rehabilitation, Pervasive and Mobile Computing, Volume 41, Pages 504-519, ISSN 1574-1192

8. Tannous, H., Istrate, D., Ho Ba Tho, M.C., Dao, T.T. (2016). Serious game and functional rehabilitation for the lower limbs, European Research in Telemedicine / La Recherche Européenne en Télémédecine, Volume 5, Issue 2, Pages 65-69.

9. Baalsrud Hauge, J.; Stefan, I. A., Stefan, A.(2017) Exploring Pervasive Entertainment Games to Construct Learning Paths, LNCS 10507 pp 196-201

10. Baalsrud Hauge, J. et al. (2017) Exploring context-aware challenges in gamified pedagogical settings, Gala conference 2017 LNCS 10653, pp 238-247

11. Barlet, Mark C, Spohn, Steve D, Drumgoole, Alicia, Mason, Jay Taylor (2012). A Practical Guide to Game Accessibility Volume 1.4

12. Judd, N. et al (2018) D4.5 Beaconing Platform GUI; https://zenodo.org/record/1256522\#.WzlP3tUzapo 